\title{
The significance of paired MEFV mutations in individuals without symptoms of familial Mediterranean fever
}

\author{
Mehmet Tunca* ${ }^{*}$, Servet Akar ${ }^{2}$, Philip N Hawkins ${ }^{4}$, Susanne E Booth ${ }^{4}$, Bülent Şengül ${ }^{1}$, \\ Tugba Ulaş Yavuzşen ${ }^{1}$, Selda Öktem ${ }^{1}$, Müjde Soytürk ${ }^{3}$, Nurullah Akkoç² and \\ David R Booth ${ }^{4}$
}

${ }^{1}$ Department of Internal Medicine, Dokuz Eylül University School of Medicine, Izmir, Turkey; ${ }^{2}$ Department of Immunology-Rheumatology, Dokuz Eylül University School of Medicine, Izmir, Turkey; ${ }^{3}$ Department of Gastroenterology, Dokuz Eylül University School of Medicine, Izmir, Turkey; ${ }^{4}$ National Amyloidosis Centre, Department of Medicine, Royal Free and University College Medical School, London, UK

The majority of patients with familial Mediterranean fever (FMF) have identifiable mutations in both alleles of the MEFV gene, while some individuals with paired MEFV mutations do not have clinical symptoms of the disease. During family studies we identified nine such individuals from six kindreds, most of whom either subsequently developed FMF or had other clinically significant inflammatory disease; one case benefiting substantially from colchicine therapy. Four individuals remained asymptomatic. Two further asymptomatic subjects with paired MEFV mutations were identified among 49 healthy controls from western Turkey, of whom a further $\mathbf{1 8 . 4}$ per cent were simple heterozygotes. This carrier rate was higher than would be expected from prevalence of FMF in this region, suggesting that penetrance of paired recognised pathogenic MEFV mutations may frequently be incomplete. MEFV genotyping results must be interpreted with due caution, and follow-up of apparently asymptomatic subjects with paired mutations is advisable.

European Journal of Human Genetics (2002) 10, 786 - 789. doi:10.1038/sj.ejhg.5200900

Keywords: familial Mediterranean fever (FMF); FMF carriers; compound heterozygotes; amyloidosis

\section{Introduction}

Familial Mediterranean fever (FMF) is an autosomal recessive disease characterised by recurrent attacks of inflammation, predominantly involving serosal and synovial membranes. ${ }^{1}$ The disease is caused by mutations in a gene named MEFV, which encodes a protein called pyrin/ marenostrin. ${ }^{2,3}$ This protein is likely to have a down-regulating influence on the response of neutrophils to inflammatory stimuli, ${ }^{4}$ and may effect survival of these cells by modulating apoptosis. ${ }^{5}$ To date, some 30 mutations in a gene named MEFV have been associated with FMF. Studies

*Correspondence: Prof Mehmet Tunca, Dokuz Eylül University School of Medicine, Department of Internal Medicine, Balçova, 35340, Izmir,

Turkey. Tel/fax: +90232279 16 26; E-mail: mehmet.tunca@deu.edu.tr or tunca@superonline.com

Received 13 June 2002; revised 6 August 2002; accepted 26 August 2002 comparing disease phenotype with MEFV genotype, ${ }^{6-9}$ indicate that some mutations are more pathogenic than others, but that clinical expression of the disease can vary widely among patients with the same mutations. Furthermore, there may be some individuals who have paired pathogenic MEFV mutations but who do not have clinical features of FMF. We report here high FMF carrier status of 49 Turkish control subjects, and the three-year clinical follow up of nine apparently healthy Turkish individuals who were found during the course of FMF family studies to be either compound heterozygotes or homozygous for potentially pathogenic FMF gene mutations.

\section{Patients and methods}

We analysed the genotypes of 116 individuals, comprising 43 FMF patients and 73 first-degree relatives of these 
patients, as part of a prospective study. Each individual was visited by us at home twice a month for 6 months and interviewed for symptoms or signs compatible with FMF or other intercurrent ailments. Later they were followed by monthly telephone calls for 3 years. All of the patients were Turks who had a diagnosis of definite FMF according to Tel-Hashomer criteria. ${ }^{1}$ In order to determine the carrier rate of FMF gene mutations among Turks generally, we also analysed the MEFV status of 49 Turkish physicians employed in our institute, none of whom had symptoms or a family history of FMF.

\section{Genotyping}

MEFV exons 3, 5 and 10 and flanking intronic sequences and the $5^{\prime}$ end of exon 2 were amplified from genomic DNA as previously described. ${ }^{10}$ PCR products were analysed using big dye terminator sequencing chemistry and an $\mathrm{ABI}$ 310 sequencing machine. Exon 10 was fully sequenced in all cases and the mutation encoding pyrin E148Q was sought by gel electrophoresis of the 5 prime exon 2 amplicon after Mval digestion. MEFV exons 10 and 5 were sequenced, and E148Q (MvaI) and P369S (AluI) status determined by RFLP for all control samples.

\section{Results}

There were five compound heterozygotes (9.6\%) and two homozygotes $(2.7 \%)$ among the 73 apparently healthy relatives of the FMF patients, and two compound heterozygous individuals (4\%) among the 49 non-FMF controls. The detected mutations and the demographic features of these nine individuals are shown in the Table 1.

There were two homozygotes. The first case, homozygous for pyrin V726A, was completely healthy and her physical examination and routine laboratory investigations were unremarkable. She was a mother of two children with FMF, one of who (an 8-year-old girl), was also a homozygous for pyrin V726A and had suffered frequent and severe attacks of FMF despite regular treatment with colchicine $1.5 \mathrm{mgr} /$ day. The other child had died of renal failure due to amyloidosis and could not be genotyped. The other

Table 1 The demographic features and genotypes of individuals with detected mutations

\begin{tabular}{llll}
\hline Pt. no. & Age/sex & Relation to FMF patient & Genotype \\
\hline 1 & $35 \mathrm{~F}$ & Mother & V726A/V726A \\
2 & $36 \mathrm{M}$ & Brother & M694V/M694V \\
3 & $15 \mathrm{M}$ & Brother* $^{*}$ & $\mathrm{M} 694 \mathrm{~V} / \mathrm{R} 761 \mathrm{H}$ \\
4 & $12 \mathrm{~F}$ & Sister $^{*}$ & $\mathrm{M} 694 \mathrm{~V} / \mathrm{E} 148 \mathrm{Q}$ \\
5 & $26 \mathrm{~F}$ & Sister & $\mathrm{M694V/M680I}$ \\
6 & $22 \mathrm{~F}$ & Sister & $\mathrm{M} 694 \mathrm{~V} / \mathrm{E} 148 \mathrm{Q}$ \\
7 & $60 \mathrm{M}$ & Father & $\mathrm{M} 680 \mathrm{I} / \mathrm{E} 148 \mathrm{Q}$ \\
8 & $27 \mathrm{M}$ & None & M694V/E148Q \\
9 & $25 \mathrm{~F}$ & None & V726A/E148Q \\
\hline
\end{tabular}

Those marked with $\left(^{*}\right)$ are related to each other. homozygous individual (pyrin M694V) had axial deformities compatible with longstanding ankylosing spondylitis. Notably this patient did not have the HLA B27 tissue type, and on further investigation was demonstrated by rectal biopsy to have AA amyloidosis and mild renal impairment with proteinuria. Although he continued to have no clinical features of FMF, he commenced treatment with colchicine $1.5 \mathrm{mgr} /$ day and his proteinuria regressed. Subject numbers 3,5 and 6 began to experience typical attacks of FMF during the last three years of follow-up. Subject 4 has experienced two short-lived episodes of monoarthritis in the lower limbs during this same period. Subject 8 reported that he had had a seronegative spondylarthropathy for several years. The remaining persons have been healthy during the follow-up period.

Among the 49 Turkish controls, 38 (77.5\%) had no identified mutations in exons 2, 3, 5 or 10 of MEFV. However, nine of these controls (18.4\%) had single mutations associated with FMF, with four carrying E148Q only, four with exon 10 mutations (V726A, M694V and K695R) and one with the exon 3 variant P369S (Table 2). There were two apparently healthy individuals who were compound pyrin heterozygotes, in one case V726A with E148Q and the other M694V plus E148Q.

\section{Discussion}

Since MEFV was identified in 1997, numerous studies have addressed the degree of correlation between genotype and phenotype among patients with FMF. In the populations most typically affected by FMF, the mutation that appears to disrupt the function of pyrin to the greatest extent encodes the M694V variant. ${ }^{11-13}$ Pyrin M694V is not only associated with a more severe clinical picture of FMF, but also confers a higher risk for these patients developing AA amyloidosis. ${ }^{13,14}$ It is therefore intriguing that amyloidosis was present in the subject we identified who was homozygous for M694V but did not have FMF (subject No: 2). This patient can be regarded as an example of one of those rare cases developing AA amyloidosis without classic signs of FMF (phenotype II). His spondylarthropathy would also

Table 2 MEFV genotypes of Turkish healthy controls

\begin{tabular}{|c|c|c|c|}
\hline Exon 10 & Exon 2 & Exon 3 & $\begin{array}{c}\text { Healthy controls } \\
n=49(\%)\end{array}$ \\
\hline $\begin{array}{l}\text { V726A } \\
\text { V726A } \\
\text { K695R } \\
\text { M694V } \\
\text { M694V }\end{array}$ & $\begin{array}{l}\text { E148Q } \\
\text { E148Q }\end{array}$ & P369S & $\begin{array}{l}1(2) \\
1(2) \\
1(2) \\
1(2) \\
2(4.1) \\
4(8.2) \\
1(2)\end{array}$ \\
\hline $\begin{array}{l}\text { No muta } \\
\text { Single m } \\
\text { Two mut }\end{array}$ & $\begin{array}{l}\text { nd } \\
\text { ound } \\
\text { und (1 }\end{array}$ & 0) & $\begin{array}{c}38(77.5) \\
9(18.4) \\
2(4.1)\end{array}$ \\
\hline
\end{tabular}


be related to FMF, as he was HLA B27 negative. Carriers of MEFV mutations have been reported to be more susceptible to developing Behçet's disease, ${ }^{15}$ and we had suggested that the presence of certain pyrin variants might increase the severity of inflammatory rheumatological diseases. ${ }^{10}$

Genetic analyses of relatives of FMF patients or certain ethnic groups have disclosed up to $4 \%$ of individuals having two MEFV mutations but not expressing FMF ('phenotype III'). ${ }^{16,17}$ Furthermore, some parents who were homozygous for E148Q mutation were completely asymptomatic. $^{18,19}$ Almost half of our subjects who were asymptomatic compound heterozygotes developed overt FMF during the relatively short follow-up period of 3 years. All of these individuals possessed an MEFV allele encoding pyrin $\mathrm{M} 694 \mathrm{~V}$, similar to a recently reported observation. ${ }^{17}$ None of the 28 relatives or two healthy controls who were demonstrated to be simple M694V carriers has yet developed overt FMF.

The significance of other MEFV mutations is less clear. The identification of an asymptomatic woman who was homozygous for pyrin V726A supports other studies suggesting that V726A homozygotes have milder forms of $\mathrm{FMF}^{20}$ However, this person had a daughter with the same mutations and very severe phenotypic expression despite optimum colchicine treatment and her son had died from amyloidosis complicating FMF. Other genetic modifier loci such as MICA (major histocompatibility complex class I chain-related gene $\mathrm{A})^{21}$ may explain these inconsistencies.

The MEFV mutation carrier rate was quite high in the Turkish healthy control group, but the prevalence was similar to that identified in another recent genotyping study. ${ }^{22}$ Twelve percent of this control group carried pyrin E148Q, and 6\% carried the M694V variant. Pyrin V726A and K695R were also detected. All these variants have been implicated in the pathogenesis of $\mathrm{FMF}^{23}$ If the observed $4 \%$ frequency of paired pathogenic MEFV mutations in the healthy control group were to apply to the Turkish population in general, in which the prevalence of FMF is about $1: 1000,{ }^{24}$ the penetrance of even the 'severe' FMF genotypes may be vastly lower than previously thought.

In conclusion, although studies comparing the phenotypes of patients with FMF with their MEFV genotypes are now quite numerous, large population genotyping studies will be required to characterise the associations of pyrin variants more widely, both with respect to the true penetrance of FMF and possibly their ability to modulate susceptibility to non-FMF inflammatory disorders. Although genotyping studies within the family of a patient with FMF are likely to have strong predictive value in excluding susceptibility to the disease when no mutations are present, the presence of an 'FMF-genotype' does not necessarily predict development of FMF.

\section{Acknowledgements}

We would like to thank our students Özlem Fatma Bıldırcın and Ișll Öztunay Önder for their invaluable assistance.

\section{References}

1 Livneh A, Langevitz P: Diagnostic and treatment concerns in familial Mediterranean fever. Baillieres Best Pract Res Clin Rheumatol 2000; 14: $477-498$.

2 International FMF Consortium: Ancient missense mutations in a new member of the RoRet gene family are likely to cause familial Mediterranean fever. Cell 1997; 90: 797-807.

3 French FMF Consortium: A candidate gene for familial Mediterranean fever. Nature Genet 1997; 17: 25: - 31 .

4 Centola M, Wood G, Frucht DM et al: The gene for familial Mediterranean fever, MEFV, is expressed in early leukocyte development and is regulated in response to inflammatory mediators. Blood 2000; 95: 3223-3231.

5 Richards N, Schaner P, Diaz A et al: Interaction between pyrin and the apoptotic spec protein (ASC) modulates ASC-induced apoptosis. J Biol Chem 2001; 276: 39320-39329.

6 Dewalle M, Domingo C, Rozenbaum M et al: Phenotype-genotype correlation in Jewish patients suffering from familial Mediterranean fever (FMF). Eur J Hum Genet 1998; 6: 95-97.

7 Livneh A, Langevitz P, Shinar Y et al: MEFV mutation analysis in patients suffering from amyloidosis of familial Mediterranean fever. Amyloid 1999; 6: 1-6.

8 Cattan D, Dervichian M, Thomas M, Dode C, Touitou I: MEFV mutations and phenotype-genotype correlations in North African Jews and Armenians with familial Mediterranean fever. Isr Med Assoc J 2001; 3: $803-804$.

9 Mansour I, Delague V, Cazeneuve C et al: Familial Mediterranean fever in Lebanon: mutation spectrum, evidence for cases in Maronites, Greek orthodoxes, Greek catholics, Syriacs and Chiites and for an association between amyloidosis and M694V and M694I mutations. Eur J Hum Genet 2001; 9: 51-55.

10 Booth DR, Lachmann HJ, Gillmore JD, Booth SE, Hawkins PN: Prevalence and significance of the familial Mediterranean fever gene mutation encoding pyrin Q148. QJM 2001; 94: 527-531.

11 Shinar Y, Livneh A, Langevitz P et al: Genotype-phenotype assessment of common genotypes among patients with familial Mediterranean fever. J Rheumatol 2000; 27: 1703-1707.

12 Akar N, Mısırlıoğlu M, Yalçınkaya F et al: MEFV mutations in Turkish patients suffering from Familial Mediterranean Fever. Hum Mutat 2000; 15: 118-119.

13 Cazeneuve C, Sarkisian T, Pecheux C et al: MEFV-gene analysis in Armenian patients with familial Mediterranean fever: Diagnostic value and unfavourable renal prognosis of the M694V homozygous genotype-genetic and therapeutic implications. Am J Hum Genet 1999; 65: 88-97.

14 Ben-Chetrit E, Backenroth R: Amyloidosis induced, end stage renal disease in patients with familial Mediterranean fever is highly associated with point mutations in the MEFV gene. Ann Rheum Dis 2001; 60: 146-149.

15 Touitou I, Magne X, Molinari N et al: MEFV mutations in Behçet's disease. Hum Mutat 2000; 16: 271-272.

16 Kogan A, Shinar Y, Lidar M et al: Common MEFV mutations among Jewish ethnic groups in Israel: high frequency of carrier and phenotype III states and absence of a perceptible biological advantage for the carrier state. Am J Med Genet 2001; 102: 272 276.

17 Gershoni-Baruch R, Shinawi M, Shamaly H, Katsinetz L, Brik R: Familial Mediterranean fever: The segregation of four different mutations in 13 individuals from one inbred family: genotypephenotype correlation and intrafamilial variability. Am J Med Genet 2002; 109: 198-201.

18 Ben-Chetrit E, Lerer I, Malamud E, Domingo C, Abeliovich D: The E148Q mutation in the MEFV gene: is it a disease-causing mutation or a sequence variant? Hum Mutat 2000; 15: 385 -386. 
19 Stoffman N, Magal N, Shohat T et al: Higher than expected carrier rates for familial Mediterranean fever in various Jewish ethnic groups. Eur J Hum Genet 2000; 8: 307-301.

20 Gershoni-Baruch R, Brik R, Shinawi M, Livneh A: The differential contribution of MEFV mutant alleles to the clinical profile of familial Mediterranean fever. Eur I Hum Genet 2002; 10: 145 - 149.

21 Touitou I, Picot MC, Domingo C et al: The MICA region determines the first modifier locus in familial Mediterranean fever. Arthritis Rheum 2001; 44: 163-169.
22 Yılmaz E, Özen S, Balcı B et al: Mutation frequency of Familial Mediterranean Fever and evidence for a high carrier rate in the Turkish population. Eur J Hum Genet 2001; 9: 553-555.

23 Touitou I: The spectrum of Familial Mediterranean Fever (FMF) mutations. Eur J Hum Genet 2001; 9: 473-483.

24 Özen S, Karaaslan Y, Özdemir O et al: Prevalence of juvenile chronic arthritis and familial Mediterranean fever in Turkey: a field study. J Rheumatol 1998; 25: 2445-2449. 